\title{
Influence of Naloxone on the Total Capacitance Vasculature of the Dog
}

Leonard Bell, Edward Maratea, and David L. Rutien

With the statistical assistance of Peter A. Charpentier and Theodore R. Holford

Cardiology Section, Department of Internal Medicine, Yale University School of Medicine, New Haven, Connecticut 06510

\section{Abstract}

The opiate antagonist, naloxone, which is associated with prolonged survival in animal models of shock, has been demonstrated to increase arterial pressure and cardiac output. It is possible that the increase in cardiac output is due to a decrease in volume in the total capacitance vasculature and a subsequent increase in venous return. Because the influence of naloxone on the capacitance vasculature is unknown, the present study was undertaken to determine the influence of naloxone on intravascular volume in the total capacitance circulation. In 31 anesthetized dogs, blood from the vena cavae was drained into an extracorporeal reservoir and returned to the right atrium at a constant rate so that changes in total intravascular volume could be measured as reciprocal changes in reservoir volume. In five animals, naloxone infusion $(2 \mathrm{mg} / \mathrm{ml} \cdot \mathrm{min}$ for $20 \mathrm{~min})$ was associated with a decrease in total capacitance volume of $121 \pm 30 \mathrm{ml}(P<0.05)$. To determine regional volume effects, naloxone was infused in 11 animals in which the splanchnic and extrasplanchnic vasculatures were separately perfused and drained: total and splanchnic volume decreased $64 \pm 13 \mathrm{ml}(P$ $<0.05)$ and $126 \pm 17 \mathrm{ml}(P<0.0001)$, respectively, and extrasplanchnic volume increased $62 \pm 13 \mathrm{ml}(P<0.001)$. After ganglionic blockade with mecamylamine $(n=3)$, total volume decreased 89 $\pm 16 \mathrm{ml}(P<0.05)$, splanchnic volume did not change, and extrasplanchnic volume decreased $91 \pm 32 \mathrm{ml}(P$ $<0.05$ ). In another five animals, naloxone was infused during diversion of the splanchnic venous outflow to a nonrecirculating extracorporeal reservoir: total volume decreased $122 \pm 33 \mathrm{ml}$ $(P<0.05)$, splanchnic volume did not change, and extrasplanchnic volume decreased $101 \pm 16 \mathrm{ml}(P<0.01)$. When the splanchnic venous effluent was reinfused without naloxone administration $(n=4)$, total volume decreased $43 \pm 5 \mathrm{ml}(P$ $<0.05)$, splanchnic volume decreased $113 \pm 14 \mathrm{ml}(P<0.05)$, and extrasplanchnic volume increased $68 \pm 10 \mathrm{ml}(P<0.05)$. Thus, naloxone is associated with a decrease in total capacitance volume, which is due entirely to a decrease in splanchnic volume. The splanchnic volume decrement would appear to be mediated through neurogenic and hormonal influences. In an animal not on bypass, it would be expected that naloxone would be associated with a decrease in total capacitance volume and subsequent increases in venous return and cardiac output.

This work was presented in part at the 1984 Scientific Session of the American College of Cardiology and was published as an abstract (1984. J. Am. Coll. Cardiol. 3:498).

Address correspondence to Dr. Rutlen.

Received for publication 11 July 1984 and in revised form 8 February 1985.

J. Clin. Invest.

(c) The American Society for Clinical Investigation, Inc.

0021-9738/85/06/1894/10 \$1.00

Volume 75, June 1985, 1894-1903

\section{Introduction}

Naloxone, an opiate antagonist, has been demonstrated to improve cardiovascular performance and prolong survival in hypotensive animals. It is possible that the improved cardiovascular performance is related, in part, to a decrease in intravascular volume in the total capacitance vasculature and a subsequent increase in venous return. Because the influence of naloxone on the capacitance vasculature has not been examined, the present study was undertaken to examine whether volume in the total capacitance vasculature is decreased during naloxone administration.

Other investigators have observed prolonged survival with naloxone administration in various hypotensive experimental conditions including endotoxin shock (1) and hypovolemic shock (2-4). The prolonged survival may be related to increases in cardiac contractility, cardiac output, and mean arterial pressure, which have been observed after administration in hypotensive animals (1-9) or patients $(10,11)$. It is also possible that the increases in cardiac output and arterial pressure are due, in part, to a decrease in capacitance volume; however, capacitance volume changes have not been previously examined.

Hence, the present study was undertaken in order to assess the influence of naloxone administration on the total capacitance vasculature. A venous bypass preparation was employed to determine regional and total intravascular volume changes and the extent to which these changes are mediated by direct, neurogenic, and hormonal influences.

\section{Methods}

Venous bypass preparation. 31 mongrel dogs of either sex, weighing between 11 and $18 \mathrm{~kg}$ (mean $14 \pm 0 \mathrm{~kg}$ ) were anesthetized with chloralose $(60-80 \mathrm{mg} / \mathrm{kg}$ iv) and urethan $(600-800 \mathrm{mg} / \mathrm{kg}$ iv), intubated, and ventilated with a mixture of room air and $100 \%$ oxygen. A median sternotomy was performed and 3,000 $\mathrm{U}$ of sodium heparin was administered iv. The experimental preparation utilized in dogs $1-10$ is illustrated in Fig. 1. The azygos vein was ligated and the superior and inferior vena cavae were cannulated with no. 32 or 34 French catheters. The total systemic venous return was drained to an overflow column and central venous pressure was adjusted by setting the height of the column at $5 \mathrm{~cm} \mathrm{H}_{2} \mathrm{O}$ with the right atrium as a reference point. The venous return was drained from the overflow column into a 2-liter no. 2022 graduated cylinder (Corning Glass Works, Corning, NY), which had 20-ml graduations. The drainage from the overflow column into the reservoir was sufficiently rapid to prevent accumulation of blood in the overflow column. From the 2 -liter graduated cylinder, blood was pumped (Travenol perfusion pump, Travenol Laboratories, Inc., Morton Grove, IL) to the right atrium via a no. 26 French catheter in the right atrial appendage at a constant rate of $350-800 \mathrm{ml} / \mathrm{min}$ (mean $579 \pm 26 \mathrm{ml} / \mathrm{min}, 89 \%$ of the perfusion rates were between 500 and $800 \mathrm{ml} / \mathrm{min}$ ). Because blood was returned to the animal at a constant rate, it was possible to record changes in volume in the total capacitance vasculature as reciprocal changes in volume in the graduated cylinder. The perfusion tubing and extracorporeal reservoir were primed with 


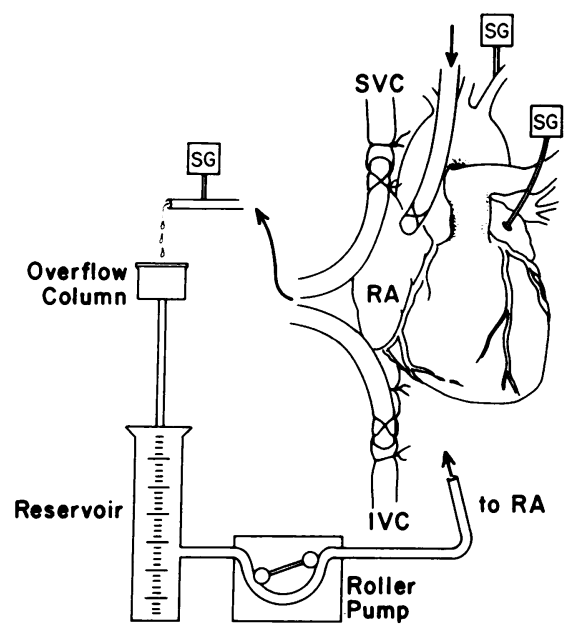

Figure 1. Experimental preparation employed. Animals were placed on venous bypass and changes in total intravascular volume were recorded as reciprocal changes in reservoir volume. See text for details. Abbreviations: SG, strain gauge; RA, right atrium; SVC, superior vena cava; IVC, inferior vena cava.

heparinized blood from two donor dogs before establishing venous bypass in each dog. Brachial arterial, left atrial, and central venous pressure were measured with Statham P23Db pressure transducers (Gould Inc., Cleveland, $\mathrm{OH}$ ). All pressures and the electrocardiogram were recorded continuously on an eight-channel, model 7758A HewlettPackard recorder (Hewlett-Packard Co., Palo Alto, CA). Volume in the graduated cylinder was recorded every minute. Arterial oxygen and carbon dioxide tensions and $\mathrm{pH}$ were determined frequently throughout the course of each experiment with a Micro-13 pH/blood gas analyzer (Instrumentation Laboratory, Inc., Lexington, MA) and were maintained at $\mathrm{pH} 7.30-7.45, \mathrm{PCO}_{2} 25-40 \mathrm{mmHg}$, and $\mathrm{PO}_{2}>100$ $\mathrm{mmHg}$.

Naloxone hydrochloride (DuPont Pharmaceuticals, Wilmington,
DE) was infused into the left atrium at a constant rate of $2 \mathrm{mg} /$ $\mathrm{ml} \cdot \mathrm{min}$ for $20 \mathrm{~min}$ (total dose $40 \mathrm{mg}$ ) on 15 occasions in dogs 1-10. 10-20 min of hemodynamic stability was observed before the start of each infusion and hemodynamic parameters were recorded for 10-20 min after each infusion was terminated. Naloxone was infused on one occasion in dogs 1-3 and on two occasions in dogs 4 and 5. Morphine sulfate (15-30 mg; A. H. Robins Co., Richmond, VA) was administered into the left atrium before eight infusions in dogs 5-10 to obtain maximal opiate receptor stimulation before administration of naloxone. Naloxone was infused after morphine on one occasion in dogs 5-8 and on two occasions in dogs 9 and 10.

Splanchnic evisceration preparation. In dogs 3-10, the influence of naloxone administration on the isolated extrasplanchnic vasculature was assessed by infusing naloxone again into the left atrium at a rate of $2 \mathrm{mg} / \mathrm{ml} \cdot \mathrm{min}$ after evisceration of the splanchnic vasculature. The preparation illustrated in Fig. 1 was modified so that exclusion of the splanchnic vasculature was accomplished by securely ligating the celiac, cranial mesenteric, and caudal mesenteric arteries and veins and all visible arteries and veins supplying the mesenteric organs. Sites of systemic anastamoses at the gastroesophageal junction and at the rectum were ligated. Running sutures were placed in the diaphragm, and the inferior mediastinum was divided. The spleen, stomach, and all intestines except the sigmoid colon were removed from the abdominal cavity, and the abdominal cavity was closed. Complete evisceration was confirmed by noting the absence of any splanchnic venous outflow in the thoracic inferior vena cava cannula in two dogs in which the abdominal inferior vena cava was ligated between the hepatic and renal veins after the conclusion of the experiment.

Separate perfusion and drainage preparation. The influence of naloxone administration on the splanchnic and extrasplanchnic vasculatures was assessed in a preparation whereby the splanchnic and extrasplanchnic vasculatures were separately perfused and drained as illustrated in Fig. 2. In 21 animals (dogs 11-31), the celiac, cranial mesenteric, and caudal mesenteric arteries were isolated and separately perfused by a perfusion pump with blood drained from a femoral artery. Splanchnic perfusion was at a constant rate of $180-300 \mathrm{ml} /$ min (mean $226 \pm 9 \mathrm{ml} / \mathrm{min}$ ) and extrasplanchnic perfusion at a constant rate of $400-700 \mathrm{ml} / \mathrm{min}$ (mean $537 \pm 32 \mathrm{ml} / \mathrm{min}$ ). An occlusive ligature was placed around the inferior vena cava below the hepatic vein, but

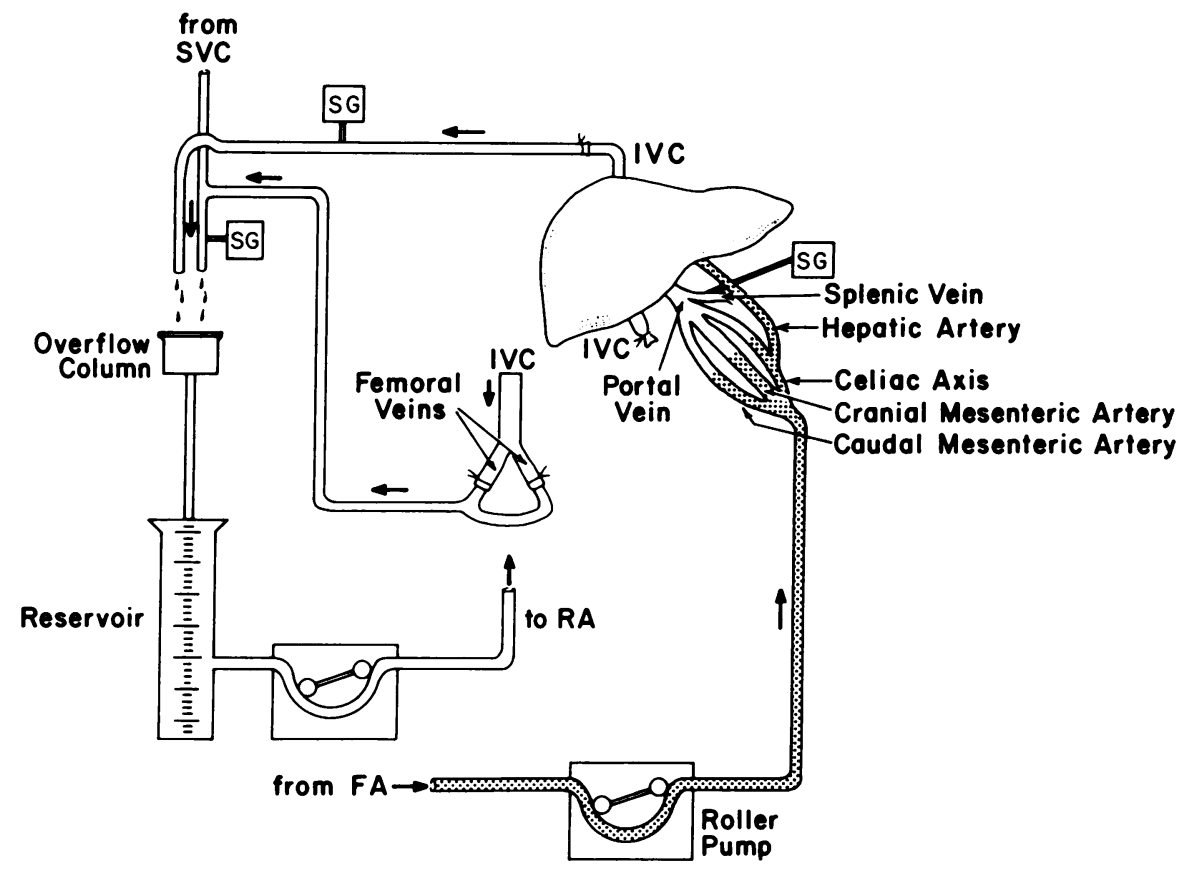

Figure 2. Experimental preparation in which the splanchnic and extrasplanchnic vasculatures were separately perfused and drained. Total, splanchnic, and extrasplanchnic volume changes were determined. See text for details. Abbreviations: SG, strain gauge; FA, femoral artery; SVC superior vena cava; IVC, inferior vena cava. 
above the renal veins, and the inferior vena cava was cannulated between the hepatic vein and the right atrium. This hepatic vein tubing, which carried the splanchnic venous outflow, was passed to an overflow column and the blood from the column was drained into the graduated cylinder. The extrasplanchnic vasculature was drained by cannulas in the superior vena cava and femoral veins. The tubing from these latter cannulas was passed to a second overflow column. Blood from this latter overflow column drained into the same graduated cylinder into which the splanchnic vasculature drained. By adjusting the heights of the overflow columns, the extrasplanchnic and hepatic venous pressures were set equal to each other at $5 \mathrm{cmH}_{2} \mathrm{O}$. To eliminate all visible shunts from the portal venous circulation to the systemic arterial circulation, running sutures were placed in the esophagus, rectum, and diaphragm and the inferior mediastinum was divided. To document the lack of visible communications between the portal and systemic circulations, latex injection fluid (Ward's Natural Science Establishment, Inc., Rochester, NY) was infused into the splanchnic arterial system in two of the animals at the conclusion of the experiment. In these animals, the latex perfused to, but not beyond the sites of occlusion. Splanchnic (portal) venous pressure was measured via a catheter advanced from a small splenic vein into the portal vein. Hepatic vein flow was determined by collecting the hepatic venous drainage in a 100- or 200-ml graduated cylinder for $30 \mathrm{~s}$ every $2 \mathrm{~min}$. Volume in the graduated cylinder was measured to the nearest $1 \mathrm{ml}$ Transhepatic venous resistance was calculated by dividing the difference between the portal and hepatic vein pressures by the hepatic vein flow. Changes in splanchnic intravascular volume were determined by integrating the difference between the mean hepatic vein flow obtained during the control period and the observed flows during and after naloxone administration. Because changes in total intravascular volume were measured as reciprocal changes in the volume of the graduated cylinder, changes in extrasplanchnic volume could be calculated as the difference between changes in total intravascular volume and changes in splanchnic intravascular volume. In 11 (dogs 11-21) of these 21 animals with separate perfusion and drainage of the splanchnic and extrasplanchnic vasculatures, naloxone, $2 \mathrm{mg} / \mathrm{ml} \cdot \mathrm{min}$, was infused into the left atrium for $20 \mathrm{~min}$ on 14 occasions. Naloxone was infused on one occasion in dogs 11-19, on two occasions in dog 20 , and on three occasions in $\operatorname{dog} 21$. In $\operatorname{dogs} 15,16$, and 20 , naloxone was infused again into the left atrium after evisceration of the splanchnic vasculature as previously described. Evisceration was confirmed in each of these three animals by noting the absence of blood flow from the hepatic vein tubing after splanchnic evisceration.

The extent to which total and regional volume changes were mediated through autonomic reflex phenomena was examined in dogs 17-19. Naloxone was infused again on one occasion in dog 17 and on two occasions in dogs 18 and 19 after ganglionic blockade had been accomplished by the administration of $200 \mathrm{mg}$ mecamylamine (Inversine; Merck, Sharpe \& Dohme, West Point, PA) to the pump reservoir over $10 \mathrm{~min}$. This dose of mecamylamine was sufficient to abolish the reflex bradycardia associated with a 300-600- $\mu \mathrm{g}$ bolus of phenylephrine hydrochloride (Neo-Synephrine Hydrochloride; Winthrop Laboratories, New York) injected into the left atrium. At least $50 \mathrm{~min}$ elapsed between mecamylamine and subsequent naloxone administration.

Splanchnic venous diversion and reinfusion preparation. Whether naloxone administration was associated with the release of a vasoactive hormone that subsequently influenced both the splanchnic and extrasplanchnic capacitance vasculatures was examined in an additional 10 animals (dogs 22-31). The experimental preparation illustrated in Fig. 2 was modified so that the splanchnic venous outflow could be diverted to another extracorporeal reservoir in order that the splanchnic outflow would not recirculate during naloxone administration. This was accomplished by attaching a Y-connector to the hepatic vein overflow column before the start of the experiment. One arm of the Y-connector drained into the 2-liter graduated cylinder while the other arm of the Yconnector drained into a separate 4-liter flask (Corning Glass Works). At the start of the experiment, the tubing draining into the separate 4 liter flask was clamped so that the splanchnic and extrasplanchnic venous returns were drained into the same graduated cylinder as in
Fig. 2. During splanchnic venous diversion, the tubing draining into the 4-liter flask was unclamped and the tubing draining into the 2-liter graduated cylinder was double-clamped so that the splanchnic venous outflow drained into the 4-liter nonrecirculating splanchnic venous reservoir. Extrasplanchnic venous outflow drained through the superior vena cava and femoral vein cannulas into the recirculating 2 -liter graduated cylinder as before. To maintain sufficient volume in the 2liter graduated cylinder while splanchnic venous outflow was being diverted to the separate nonrecirculating reservoir, donor blood was transferred from a separate 10 -liter container to the 2-liter graduated cylinder. The mean hematocrits for the donor blood, 2-liter graduated cylinder blood, and 4-liter nonrecirculating splanchnic reservoir blood were $31.5 \pm 1,32.5 \pm 1$, and $32 \pm 2 \%$, respectively. These values were not significantly different from each other. Changes in splanchnic volume were determined as described previously. Changes in extrasplanchnic volume were calculated by collecting the extrasplanchnic venous outflow in a graduated cylinder for $30 \mathrm{~s}$ every $2 \mathrm{~min}$ and then integrating the difference between the mean extrasplanchnic venous flow obtained during the control period and the observed flows during and after naloxone administration. Changes in volume in the total capacitance vasculature were calculated by adding the splanchnic and extrasplanchnic volume changes. Naloxone, $2 \mathrm{mg} / \mathrm{ml} \cdot \mathrm{min}$, was infused into the left atrium for $20 \mathrm{~min}$ without diversion and again during diversion of the splanchnic venous outflow in dogs 22-26. In $\operatorname{dog} 27$, naloxone was first infused during splanchnic venous diversion.

In dogs 24-27, the influence of the diverted splanchnic venous effluent on extrasplanchnic volume was examined directly by reinfusing the splanchnic venous effluent after splanchnic evisceration had been accomplished. The splanchnic vasculature was eviscerated in each of these four animals as described previously. After a 10-20-min precontrol period was obtained, blood that had been stored in the nonrecirculating splanchnic venous reservoir during the previous naloxone infusion was added to the 2-liter graduated cylinder over a 20 -min period without concurrent naloxone administration. Changes in extrasplanchnic vascular volume were determined as in the previous set of experiments.

In dogs 28-31, naloxone was first administered during splanchnic venous diversion and the diverted splanchnic outflow was then reinfused over a 20-min period without concurrent naloxone administration and without prior abdominal evisceration. Changes in total, splanchnic, and extrasplanchnic volumes were examined by measuring changes in splanchnic and extrasplanchnic venous outflow as described previously.

Whether the diversion and reinfusion technique alone influenced the present observations was examined in dogs 28 and 29. At the beginning of each study, total and regional volume changes were examined during $20 \mathrm{~min}$ of diversion without naloxone administration and then during $20 \mathrm{~min}$ of reinfusion of the previously diverted splanchnic venous outflow.

To determine whether shifts in fluid volume between the intravascular and extravascular spaces may have influenced the observed volume changes, hematocrits were determined on four occasions before and after naloxone administration.

Brief naloxone infusions. Whether the total and regional volume responses associated with naloxone administration could be observed to return to precontrol levels during the postcontrol period, after a shorter duration of naloxone administration, was examined in dogs 30 and 31. In each of these two animals, splanchnic and extrasplanchnic venous outflows were measured and total, splanchnic, and extrasplanchnic volume changes were calculated during naloxone administration $(2 \mathrm{mg} / \mathrm{ml} \cdot \mathrm{min})$ for $14 \mathrm{~min}$ and during a 30-35-min postcontrol period after the termination of naloxone administration.

Effect of ganglionic blockade. In four other animals, the influence of ganglionic blockade alone was assessed by measuring reservoir volume and mean arterial pressure before and after the administration of $150-200 \mathrm{mg}$ of mecamylamine.

Statistical analysis. To calculate the change in total intravascular volume, a line of best fit was determined by linear regression analysis for the reservoir volume recordings obtained during the 10-20-minute period before each drug infusion. The synthetic variable, the deviation from the line of best fit, was determined at all points in time before, 
during, and after naloxone administration. This synthetic variable was assumed to represent change in total intravascular volume. Means \pm standard errors of the means were determined for each hemodynamic parameter at each point in time for experiments performed under similar experimental conditions.

Because simple analysis of variance requires equal variances among means, a quantitative test for heteroscedasticity (unequal variances among means) of the precontrol, experimental, and postcontrol means was performed for each parameter in each experimental group. The appropriate one-way analysis of variance model was determined, in accordance with the particular heteroscedasticity test results, and then performed as described by Sokal and Rohlf (12) using standard statistical software (13). For the analysis of variance when variances were unequal, a heteroscedastic population, each mean was weighted by the inverse of its observed variance. For each hemodynamic parameter in each experimental group, an initial global comparison was first performed between all control and experimental values in order to test the proposition $\mathrm{H}_{0}$ : All mean values are equal. Only if this global comparison was significant (i.e., $\mathrm{H}_{0}$ was rejected) were values at individual points in time examined. In such cases, control means were compared with experimental values obtained at 10,20, and $30 \mathrm{~min}$ by employing $t$ tests at each selected point. The mean square derived from the previous global analysis of variance was used and adjustment for multiple comparisons was made by the method of Bonferroni (14). All data presented in Figs. 3-7 were initially analyzed by comparing hemodynamic changes obtained at the end of naloxone infusion with the control hemodynamic values obtained prior to drug infusion by means of Student's paired $t$ tests. All changes subsequently demonstrated to be statistically significant at the end of infusion by analysis of variance were also significant by a paired Student $t$ test. Changes in hemodynamic parameters at the end of infusions, performed before pharmacologic or surgical intervention, were also compared with changes after interventions by a paired or unpaired Student $t$ test. (An unpaired test was used for the before and after ganglionic blockade data.) In cases in which sample means had unequal variances, comparisons were performed using the Behrens-Fischer modification of the $t$ tests (12).

Paired Student $t$ tests were used to compare total and regional volume changes obtained at the termination of consecutive naloxone infusions, volume and mean arterial pressure changes associated with the termination of naloxone administration when base-line arterial pressure was $>70 \mathrm{mmHg}$, volume changes before and after evisceration in three animals with separate perfusion and drainage, volume and arterial pressure changes associated with mecamylamine administration, and hematocrit changes.

Statistical significance was assumed as $P<0.05$ in all calculations.

\section{Results}

The mean data associated with seven periods of naloxone infusion in five animals, without the prior administration of exogenous opiates, are presented in Fig. 3. Naloxone infusion was associated with a decrease in volume in the total capacitance vasculature of $121 \pm 30 \mathrm{ml}(P<0.05)$ and an increase in mean arterial pressure from $60 \pm 6$ to $66 \pm 7 \mathrm{mmHg}$ (NS) at the end of the 20-min infusion. During the eight infusions in five dogs in which morphine had been previously administered, naloxone was associated with a $74 \pm 29 \mathrm{ml}(P<0.05)$ volume decrement and an increase in mean arterial pressure from $58 \pm 3$ to $67 \pm 4$ $\mathrm{mmHg}(P<0.05)$.

In five animals (dogs $1,3,16,18$, and 21$)$, in which the base-line mean arterial pressure was $>70 \mathrm{mmHg}$ and in which morphine had not been previously administered, naloxone was associated with a decrease in total intravascular volume of $55 \pm 8 \mathrm{ml}(P<0.01)$. Mean systemic arterial pressure increased from $78 \pm 2$ to $88 \pm 5(P<0.05)$. In the three of these animals with separate perfusion and drainage $(16,18$, and 21$)$, splanch-
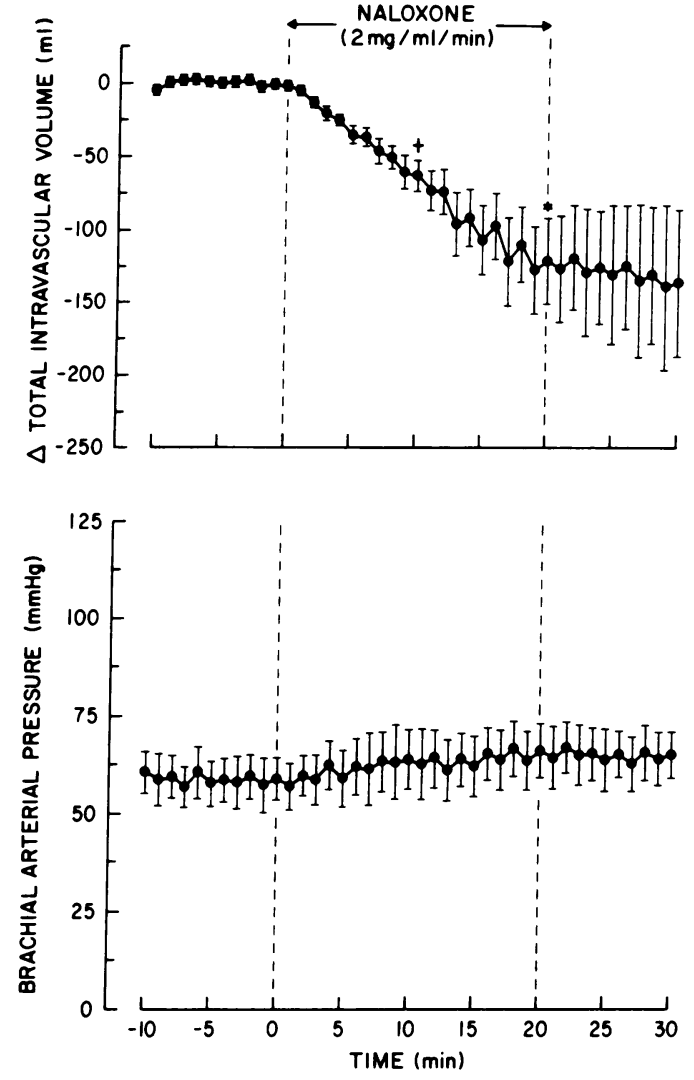

Figure 3. Effect of naloxone infusion, without the prior administration of exogenous opiates, on total intravascular volume and mean systemic arterial pressure. Note the prompt and sustained decrease in total intravascular volume associated with naloxone administration. For the global comparison, $\mathrm{F}_{6,36}=11.20, P<0.0001$. The indications of significance in the figure apply only to the data points determined at 10,20 , and 30 min. Each bar represents \pm 1 SEM. ${ }^{*}, P$ $<0.05 ;+, P<0.01 ; n=7$.

nic volume decreased $88 \pm 14 \mathrm{ml}(P<0.05)$ and extrasplanchnic volume increased $47 \pm 8 \mathrm{ml}(P<0.05)$.

Naloxone was associated with decreases in total intravascular volume both before and after splanchnic evisceration. Intravascular volume decreased $69 \pm 13 \mathrm{ml}(P<0.01)$ before splanchnic evisceration and $85 \pm 23 \mathrm{ml}(P<0.05)$ after evisceration in eight dogs. Mean arterial pressure increased from $63 \pm 4$ to $72 \pm 6 \mathrm{mmHg}(P<0.05)$ before evisceration and from $77 \pm 6$ to $86 \pm 9 \mathrm{mmHg}$ (NS) after evisceration. In the three animals with separate perfusion and drainage of the splanchnic and extrasplanchnic vasculatures, naloxone administration was associated with a $44 \pm 20 \mathrm{ml}$ (NS) extrasplanchnic volume increment before splanchnic evisceration and a $69 \pm 18 \mathrm{ml}$ (NS) extrasplanchnic volume decrement after evisceration. The extrasplanchnic volume responses before and after splanchnic evisceration differed significantly $(P<0.005)$.

The data associated with naloxone infusion in animals with separate perfusion and drainage of the splanchnic and extrasplanchnic vasculatures without prior intervention are presented in Fig. 4. Naloxone infusion was associated with decreases in both total and splanchnic intravascular volume of $64 \pm 13 \mathrm{ml}(P<0.05)$ and $126 \pm 17 \mathrm{ml}(P<0.0001)$, respectively, and with an increase in extrasplanchnic volume of $62 \pm 13 \mathrm{ml}(P<0.001)$ during 14 infusions in 11 dogs. Splanchnic venous outflow increased from $0.184 \pm 0.008$ to $0.192 \pm 0.009$ 

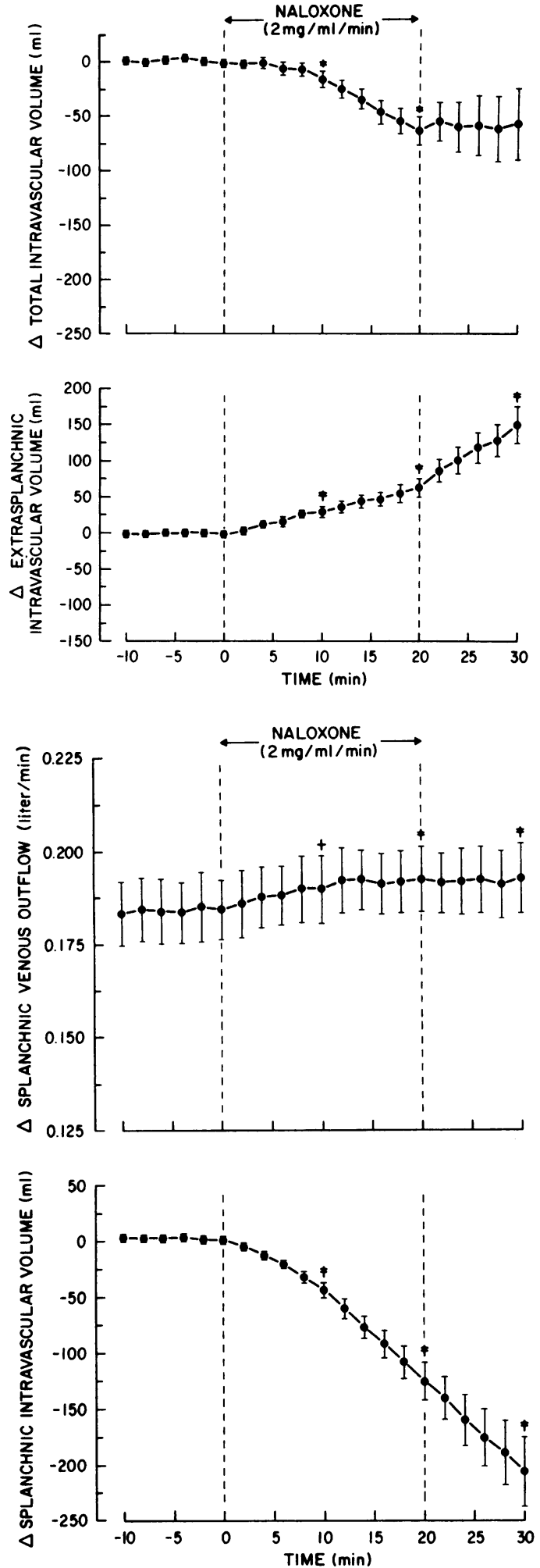

Figure 4. Effect of naloxone administration under conditions of separate perfusion and drainage of the splanchnic and extrasplanchnic vasculatures. Note that while total $\left(F_{7,38}=8.72\right.$, $P<0.0001)$ and splanchnic intravascular volumes $\left(F_{7,39}=45.25\right.$, $P<0.0001)$ decreased, extrasplanchnic vascular volume $\left(\mathrm{F}_{7,39}\right.$ $=21.61, P<0.0001$ ) increased during naloxone administration. Each bar represents \pm 1 SEM. Although the increase in splanchnic venous outflow appears small, the change was significant $\left(F_{7,40}\right.$ $=23.95, P<0.0001$ ) since flow increased during each infusion. ${ }^{*}, P$ $<0.05 ;+, P<0.01 ; \ddagger, P<0.001 ; n=14$. liter/min $(P<0.001)$. Mean systemic arterial pressure increased from $63 \pm 3$ to $71 \pm 4 \mathrm{mmHg}(P<0.01)$ while portal pressure (increase from $15 \pm 1$ to $16 \pm 1 \mathrm{cmH}_{2} \mathrm{O}$ ) and hepatic resistance (decrease from $59 \pm 16$ to $58 \pm 7 \mathrm{cmH}_{2} \mathrm{O} \cdot \mathrm{min} / \mathrm{liter}$ ) did not change significantly.

In two animals in which naloxone was administered for only $14 \mathrm{~min}$ and in which a longer postcontrol period was observed, regional and total volumes had begun to return towards precontrol levels by 6-14 min after termination of infusion and had returned completely to precontrol levels by the end of the postcontrol period.

Repetitive infusion of naloxone was not associated with a significant attenuation of the total or regional volume responses. In four animals in which morphine had not been previously administered, repetitive naloxone infusion on five occasions was associated with decreases in total intravascular volume of $99 \pm 41$ (NS) and $74 \pm 23 \mathrm{ml}(P<0.05)$, respectively. These changes were not significantly different from each other. In the two of these animals with separate perfusion and drainage, repetitive drug administration on three occasions was associated with decreases in splanchnic volume of $92 \pm 40$ (NS) and $75 \pm 16$ $\mathrm{ml}(P<0.05)$ and with increases in extrasplanchnic volume of $47 \pm 29$ (NS) and $35 \pm 24 \mathrm{ml}(\mathrm{NS})$. These changes did not differ significantly.

The data associated with naloxone infusion before and after ganglionic blockade in three animals with separate perfusion and drainage of the splanchnic and extrasplanchnic vasculatures are presented in Fig. 5. Naloxone infusion was associated with a total intravascular volume decrement of $104 \pm 34 \mathrm{ml}$ (NS) before ganglionic blockade which did not differ significantly from the $89 \pm 16 \mathrm{ml}(P<0.05)$ decrement after blockade. The splanchnic intravascular volume decrement of $171 \pm 31 \mathrm{ml}(P<0.05)$ before ganglionic blockade was abolished after blockade. These responses were significantly different from each other $(P<0.05)$. The extrasplanchnic volume increment of $67 \pm 9 \mathrm{ml}(P<0.0001)$ during naloxone infusion before ganglionic blockade was significantly different $(P<0.05)$ from the volume decrement of $91 \pm 32 \mathrm{ml}(P$ $<0.05$ ) after blockade. Mean systemic arterial pressure increased from $64 \pm 7$ to $77 \pm 1 \mathrm{mmHg}$ (NS) before blockade and decreased from $104 \pm 12$ to $89 \pm 5 \mathrm{mmHg}$ (NS) after blockade. Hepatic resistance and portal pressure did not change significantly before or after blockade.

In Fig. 6 the data associated with naloxone infusion with and without diversion of the splanchnic venous outflow in five dogs are presented. Naloxone was associated with a total intravascular volume decrement of $40 \pm 14 \mathrm{ml}(P<0.05)$ without splanchnic venous diversion. This value did not differ significantly from the $122 \pm 33 \mathrm{ml}(P<0.05)$ decrement with diversion. The splanchnic intravascular volume decrement of $132 \pm 28 \mathrm{ml}(P<0.05)$ without splanchnic venous diversion was abolished during naloxone infusion with diversion. These responses were significantly different from each other $(P<0.05)$. The extrasplanchnic volume increment of $92 \pm 20 \mathrm{ml}(P<0.05)$ during naloxone infusion without splanchnic venous diversion was significantly different $(P<0.001)$ from the extrasplanchnic volume decrement of $101 \pm 16 \mathrm{ml}(P<0.01)$ with diversion. Mean systemic arterial pressure increased from $61 \pm 10$ to $72 \pm 10 \mathrm{mmHg}(P<0.01)$ during naloxone without splanchnic venous diversion but did not change significantly during naloxone infusion with diversion. Hepatic resistance and portal venous pressure did not change significantly during naloxone 

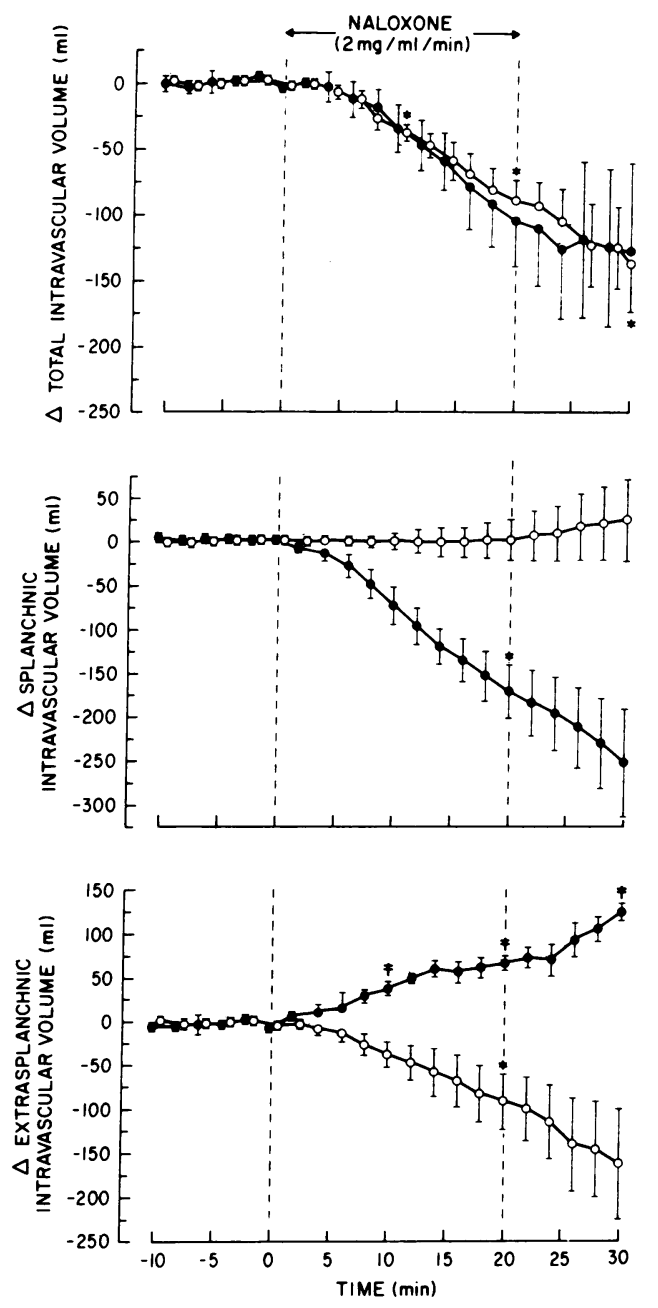

Figure 5. Effect of naloxone administration before and after ganglionic blockade under conditions of separate perfusion and drainage of the splanchnic and extrasplanchnic vasculatures. Top, the total intravascular volume decrements before $\left(F_{7,38}=28.37, P<0.0001\right)$ and after $\left(F_{7,12}=12.51, P<0.0001\right)$ blockade did not differ significantly. Middle, the splanchnic volume decrement before blockade $\left(\mathrm{F}_{7,6}\right.$ $=13.08, P<0.01)$ differed significantly $(P<0.05)$ from the insignificant change after blockade $\left(\mathrm{F}_{7,12}=0.05, \mathrm{NS}\right)$. Bottom, the extrasplanchnic volume increment before blockade $\left(\mathrm{F}_{7,38}=28.37, P\right.$ $<0.0001)$ differed significantly $(P<0.05)$ from the volume decrement after blockade $\left(\mathrm{F}_{7,12}=4.58, P<0.01\right)$. Each bar represents \pm 1 SEM. ${ }^{*}, P<0.05 ; \ddagger, P<0.001 ;(\bullet)$, before ganglionic blockade $(n$ $=3)$; (O), after ganglionic blockade $(n=5)$.

administration either with or without splanchnic venous diversion.

The data obtained in four dogs during splanchnic venous diversion with naloxone administration and during subsequent reinfusion of the previously diverted splanchnic outflow for $20 \mathrm{~min}$ without concurrent naloxone administration are presented in Fig. 7. The total volume decrement of $71 \pm 10 \mathrm{ml}(P$ $<0.05$ ) during naloxone infusion with splanchnic diversion did not differ significantly from the total volume decrement of $43 \pm 5 \mathrm{ml}(P<0.05)$ during reinfusion of the splanchnic outflow. The absence of a significant splanchnic volume change during naloxone with diversion was significantly different $(P$ $<0.01$ ) from the splanchnic volume decrement of $113 \pm 14 \mathrm{ml}$ $(P<0.05)$ during splanchnic venous reinfusion. The extra-
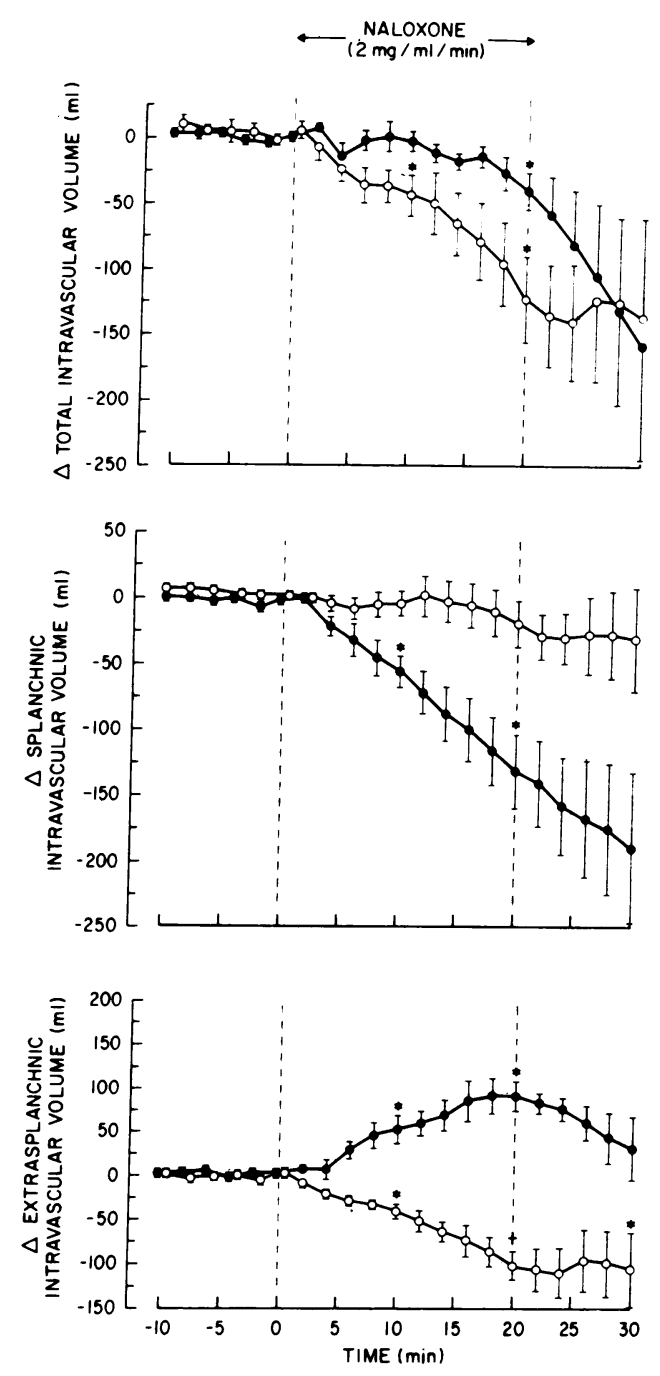

Figure 6. Effect of naloxone administration under conditions of separate perfusion and drainage of the splanchnic and extrasplanchnic vasculatures before and during diversion of the splanchnic venous outflow to a nonrecirculating extracorporeal reservoir. Top, total intravascular volume decreased both with $\left(\mathrm{F}_{7,12}=7.57, P\right.$ $<0.001)$ and without $\left(\mathrm{F}_{7.12}=4.34, P<0.05\right)$ splanchnic diversion. Middle, the splanchnic volume decrement during naloxone infusion without diversion $\left(\mathrm{F}_{7,12}=10.92, P<0.001\right)$ differed significantly $(P$ $<0.05)$ from the insignificant change with diversion $\left(F_{7,12}=1.06\right.$, NS). Bottom, the extrasplanchnic volume increment during naloxone infusion without diversion $\left(\mathrm{F}_{7,12}=11.31, P<0.001\right)$ differed significantly $(P<0.001)$ from the volume decrement with splanchnic venous diversion $\left(\mathrm{F}_{7.12}=14.75, P<0.0001\right)$. Each bar represents \pm 1 SEM. ${ }^{*}, P<0.05 ;+, P<0.01 ;(\bullet)$, without splanchnic diversion $(n$ $=5)$; (O), with splanchnic diversion $(n=5)$.

splanchnic volume decrement of $75 \pm 8 \mathrm{ml}(P<0.05)$ during naloxone infusion with splanchnic diversion was significantly different $(P<0.01)$ from the extrasplanchnic volume increment of $68 \pm 10 \mathrm{ml}(P<0.05)$ during splanchnic reinfusion. Mean arterial pressure decreased from $65 \pm 5$ to $55 \pm 5 \mathrm{mmHg}$ (NS) during naloxone with splanchnic diversion and increased from $57 \pm 6$ to $75 \pm 7 \mathrm{mmHg}$ (NS) during splanchnic reinfusion.

In four animals with splanchnic venous diversion and with subsequent reinfusion of the splanchnic venous effluent in the same dogs after evisceration, the extrasplanchnic volume dec- 

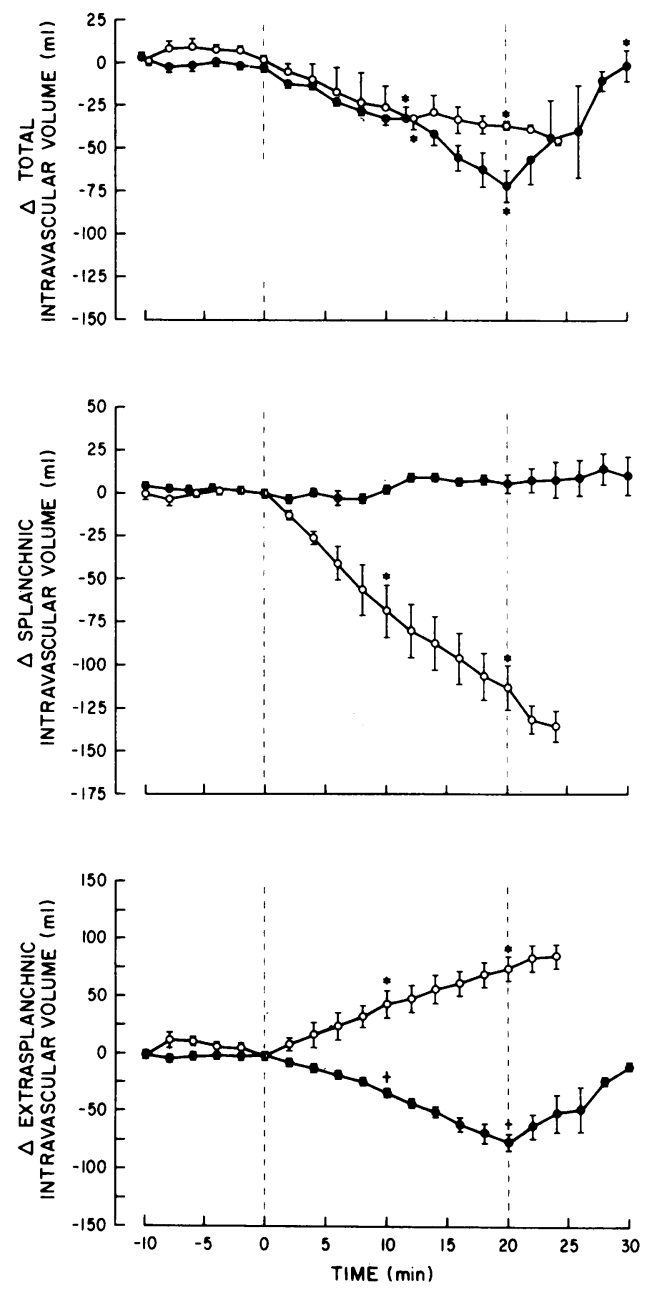

Figure 7. Effects of naloxone administration with splanchnic venous diversion and effects of reinfusion of the splanchnic venous outflow without concurrent naloxone administration. The previously diverted splanchnic venous outflow was reinfused into the animal during the period of 0-20 min. Top, total intravascular volume decreased during both naloxone administration with diversion $\left(\mathrm{F}_{7,12}=9.89, P\right.$

$<0.001)$ and during reinfusion without naloxone administration $\left(\mathrm{F}_{7,12}=10.23, P<0.0001\right)$. Middle, the insignificant splanchnic volume change with diversion $\left(F_{7,12}=1.13\right.$, NS) differed significantly $(P<0.01)$ from the decrement during reinfusion $\left(\mathrm{F}_{7,12}=11.12, P<\right.$ $0.001)$. Bottom, the extrasplanchnic yolume decrement with naloxone during diversion $\left(\mathrm{F}_{7,12}=10.96, P<0.001\right)$ differed significantly $(P$ $<0.01)$ from the volume increment during reinfusion $\left(\mathrm{F}_{7,12}=10.26\right.$, $P<0.01$ ). Each bar represents \pm 1 SEM. ${ }^{*}, P<0.05 ;+, P<0.01$; $(\bullet)$, naloxone infusion with splanchnic diversion $(n=4)$; (०), splanchnic venous effluent reinfusion $(n=4)$.

rement of $93 \pm 16 \mathrm{ml}(P<0.05)$ during naloxone infusion with splanchnic diversion was significantly different $(P<0.001)$ from the extrasplanchnic volume increment of $71 \pm 7 \mathrm{ml}(P$ $<0.01$ ) during reinfusion without naloxone administration. Mean systemic arterial pressure did not change significantly with splanchnic effluent reinfusion (increase from $64 \pm 6$ to $70 \pm 9 \mathrm{mmHg}$ ).

In two animals, diversion of the splanchnic venous outflow, without concurrent naloxone administration, and subsequent reinfusion of the previously diverted outflow were associated with total, splanchnic, and extrasplanchnic volume changes of $<9 \mathrm{ml}$.
In the four animals in which the influence of mecamylamine was examined, mean arterial pressure decreased from $66 \pm 8$ to $47 \pm 4 \mathrm{mmHg}(P<0.05)$ by $7 \pm 2$ minutes (range $2-10 \mathrm{~min}$ ) after mecamylamine administration. At the time of this maximal effect on arterial pressure, total intravascular volume had increased $22 \pm 23 \mathrm{ml}$ (NS). It would appear that the total intravascular volume change had stabilized by this time, in that the volume change $5 \mathrm{~min}$ later was $18 \pm 22 \mathrm{ml}$ (NS) compared to control.

In four animals, shifts in fluid volume between the intravascular and extravascular spaces were not detected by a change in hematocrit measured before and after naloxone administration: hematocrit increased only from $32.5 \pm 2$ to $32.7 \pm 1 \%$ (NS).

Heteroscedasticity was noted for all hemodynamic changes in all experimental groups except for the following categories: extrasplanchnic volume in dogs 17-19 before mecamylamine administration; mean systemic arterial pressure in dogs 24-27 during splanchnic venous diversion; and splanchnic venous flow in dogs 17-19 after mecamylamine administration, in dogs 22-26 before splanchnic diversion, in dogs 24-27 during splanchnic diversion, and in dogs 28-31 during diversion and reinfusion. Further analysis of representative data groups (dogs 11-21 and 28-31), by two-way analysis of variance and by incorporating the regression analysis into the analysis of variance, demonstrated that the heteroscedasticity was due to the variance among individual trials as well as the variance resulting from the extrapolation of the regression line obtained during the precontrol period to the experimental and postcontrol periods. Analysis of variance, after accounting for these variables, demonstrated that the effect of time was still significant (i.e., $\mathrm{H}_{0}$ was rejected), as were the changes at 10 and $20 \mathrm{~min}$.

The directional changes in total and regional intravascular volumes during naloxone administration under each experimental condition are summarized in Table $\mathbf{I}$.

\section{Discussion}

The present data demonstrate that naloxone administration is associated with a decrease in intravascular volume in the total capacitance vasculature. The total volume decrement is due to a decrease in splanchnic intravascular volume and occurs despite an increase in extrasplanchnic volume. The data also suggest the mechanisms responsible for the total and regional volume responses.

The series of experiments in animals with separate splanchnic perfusion and drainage suggest the extent to which the splanchnic volume decrement is due to neurogenic and hormonal influences. A naloxone-initiated neurogenic reflex is necessary for the volume decrement to occur in that the decrement was abolished after ganglionic blockade. Furthermore, it would appear that the neurogenic reflex acts to release a vasoactive splanchnic hormone which recirculates to mediate the splanchnic volume decrement, inasmuch as the splanchnic volume response was abolished by splanchnic venous outflow diversion and was reestablished with reinfusion of the previously diverted splanchnic outflow. Naloxone is not associated with a direct effect on the splanchnic capacitance vasculature, because splanchnic volume did not change during naloxone administration after either ganglionic blockade or during diversion of the splanchnic venous effluent.

The extrasplanchnic volume increment is also apparently dependent upon both neurogenic and hormonal effects, al- 
Table I. Total and Regional Volume Changes

Associated with Naloxone Administration

under Different Experimental Conditions*

\begin{tabular}{|c|c|c|c|}
\hline Experimental condition & $\begin{array}{l}\text { Total } \\
\text { volume }\end{array}$ & $\begin{array}{l}\text { Splanchnic } \\
\text { volume }\end{array}$ & $\begin{array}{l}\text { Extra- } \\
\text { splanchnic } \\
\text { volume }\end{array}$ \\
\hline \multicolumn{4}{|l|}{ Venous bypass, prior morphine } \\
\hline administration & $\downarrow$ & & \\
\hline Venous bypass & $\downarrow$ & & \\
\hline After abdominal evisceration & & & $\downarrow$ \\
\hline \multicolumn{4}{|l|}{$\begin{array}{l}\text { Separate perfusion and } \\
\text { drainage of splanchnic }\end{array}$} \\
\hline circulation & $\downarrow$ & $\downarrow$ & $\uparrow$ \\
\hline Ganglionic blockade & $\downarrow$ & - & $\downarrow$ \\
\hline Splanchnic venous diversion & $\downarrow$ & - & $\downarrow$ \\
\hline \multicolumn{4}{|l|}{$\begin{array}{l}\text { Subsequent splanchnic } \\
\text { reinfusion without }\end{array}$} \\
\hline naloxone & $\downarrow$ & $\downarrow$ & $\uparrow$ \\
\hline $\begin{array}{l}\text { Subsequent splanchnic } \\
\text { reinfusion without } \\
\text { naloxone, after abdominal }\end{array}$ & & & \\
\hline evisceration & & & $\uparrow$ \\
\hline \multicolumn{2}{|l|}{ Splanchnic venous diversion } & - & - \\
\hline $\begin{array}{l}\text { Subsequent splanchnic } \\
\text { reinfusion without }\end{array}$ & & & \\
\hline naloxone & - & - & - \\
\hline
\end{tabular}

* $\downarrow$, decrement; $\uparrow$, increment; -, no change.

though the increment occurs despite a direct influence of naloxone to decrease extrasplanchnic volume. A naloxoneinitiated autonomic reflex is necessary for the volume increment to occur, because the extrasplanchnic volume increment was abolished after ganglionic blockade. It would appear that a vasoactive hormone is subsequently released from the splanchnic vasculature and acts to increase extrasplanchnic volume, because the extrasplanchnic volume increment was abolished by diversion of the splanchnic venous effluent or by abdominal evisceration and was reestablished by reinfusion of the previously diverted splanchnic outflow in both the intact and eviscerated animals. Naloxone is also associated with a direct effect that acts to decrease extrasplanchnic volume, because naloxone administration was associated with decreases in extrasplanchnic volume after ganglionic blockade, splanchnic venous diversion, or abdominal evisceration.

Because mecamylamine administration is known to have significant effects on the circulation, one might argue that the volume changes associated with naloxone administration after ganglionic blockade were due to the effects of mecamylamine alone. However, this interpretation is unlikely for the following reasons. First, the maximal arterial pressure and intravascular volume effects appeared within $10 \mathrm{~min}$ of mecamylamine administration, whereas naloxone administration did not begin until at least $50 \mathrm{~min}$ after mecamylamine administration. Second, $20 \mathrm{~min}$ of hemodynamic stability was documented before the onset of all naloxone infusions after mecamylamine administration. Finally, the total volume response associated with mecamylamine alone was directionally different from the response associated with naloxone administration after ganglionic blockade.
One might argue also that mecamylamine enhances the metabolism of naloxone so that it is immediately removed from the circulation, inasmuch as the splanchnic volume responses were abolished either after ganglionic blockade or during removal of naloxone from the circulation by splanchnic venous diversion. However, not all of the administered naloxone is removed by the splanchnic venous diversion. Furthermore, a drug effect is still manifest during naloxone administration after mecamylamine or during diversion, as noted by the decreases in extrasplanchnic volume.

Although the present study would suggest that the efferent limb of the neurogenic reflex, which mediates the splanchnic and extrasplanchnic volume responses, acts in the splanchnic vasculature, several previous studies suggest that the afferent limb receptors are located in the central nervous system. Bolme et al. (15) observed a transient hypertensive response to the intraventricular injection of naloxone in chloralose-anesthetized rats. Laubie et al. (16) observed that intracisternal injection of opioid peptides was associated with a decrease in splanchnic sympathetic nerve discharges which was reversed by intravenous naloxone in dogs. In addition, Faden and Holaday (1) demonstrated that intraventricular administration of naloxone in rats with surgically transected cervical spinal cords was associated with a reversal of acute hypotension.

The efferent limb of the autonomic reflex, which mediates the present regional intravascular volume changes, could be constituted by either sympathetic or parasympathetic fibers, because Laubie et al. (16) demonstrated an increase in splanchnic sympathetic tone with naloxone, and observations by Faden and Holaday (1) are consistent with a decrease in cardiac parasympathetic tone during naloxone administration.

Possible hormonal substances, which might be released by the naloxone initiated neurogenic reflex and act on the capacitance vasculature, include norepinephrine, epinephrine, dopamine, or acetylcholine. However, $\alpha$ - and $\beta$-adrenergic receptor stimulation with norepinephrine or epinephrine would be expected to be associated with changes in portal pressure and hepatic resistance $(17,18)$ which were not observed. Furthermore, Feuerstein et al. (8) did not observe changes in plasma norepinephrine or epinephrine during naloxone administration in hypovolemic rats. Although plasma dopamine has been observed to increase during naloxone administration in cats with spinal chord transection (7), Feuerstein et al. did not observe such changes. Acetylcholine release would be expected to be associated with increases in hepatic resistance, portal pressure, and splanchnic volume (19). However, hepatic resistance and portal pressure did not change although splanchnic volume decreased during naloxone administration. Hence, the identity of the hormonal substance is not suggested by data obtained from either the present study or other studies. It is possible that the substance is a vasoactive peptide released from the gastrointestinal wall.

In addition to the neurogenic and hormonal influences of naloxone on the splanchnic and extrasplanchnic vasculatures, naloxone administration has a direct effect on the extrasplanchnic vasculature. Prior work has demonstrated the presence of opiate receptors in multiple sites in the central nervous system (20) and in such peripheral tissues as guinea pig ileum, mouse vas deferens, and rat vas deferens (20-22). Furthermore, Curtis and Lefer (5) have demonstrated a modest positive inotropic effect of high concentrations of naloxone in cat papillary muscle. In addition to the demonstration of opiate receptors at multiple sites, at least five distinct opiate receptor 
types, which differ in their affinity for various agonists and antagonists, have been identified in the central nervous system and in peripheral tissues (22). The existence of naloxonesensitive receptors in vascular smooth muscle has not been documented previously. The present study suggests the existence of such opiate receptors in the extrasplanchnic capacitance vasculature of the dog.

The observation that total and regional intravascular volume changes did not return towards precontrol levels after termination of the infusion may have been related to both the cumulative amount of naloxone administered for $20 \mathrm{~min}$ and to the relatively short postcontrol period. This hypothesis is supported by our observation that total, splanchnic, and extrasplanchnic volume changes returned to precontrol levels in the two animals in which naloxone was infused for only 14 min and in which hemodynamic monitoring was continued for a longer postcontrol period.

The presently observed base-line mean arterial pressure of $60 \mathrm{mmHg}$ is comparable to the base-line values observed by other investigators who have examined the influence of naloxone on survival in hypotensive animals not on bypass (1-4, 9). However, even though the present base-line pressure is comparable to that in hypotensive animals not on bypass, the present total and regional intravascular volume responses are not dependent upon this lower pressure, because the total and regional volume changes are similar in animals with higher and lower base-line arterial pressures.

It might have been expected that prior administration of an exogenous opiate would be necessary to demonstrate a naloxone-associated total intravascular volume change. However, the present data demonstrate that such administration is not necessary either at lower or higher base-line arterial pressures. Furthermore, the regional volume changes and the neurogenic and hormonal influences that apparently mediate these changes are not dependent upon prior opiate administration. A possible explanation for this observation is that the surgery required for the bypass preparation was extensive enough to cause release of endogenous opiates and subsequent naloxone administration reversed the effects of these opiates. Such an explanation is consistent with the work of Dashwood and Feldberg (23) in that they observed arterial pressure increments associated with naloxone administration alone, after extensive surgery. While Dashwood and Feldberg suggest that the arterial pressure response is dependent upon the release of adrenal hormones, our data would suggest that the intravascular volume response is dependent upon the release of a splanchnic hormone.

The mean arterial pressure increase observed in the present study is less than that reported by other investigators (1-4), who infused naloxone at similar rates $(0.5-2.0 \mathrm{mg} / \mathrm{min})$. This difference may be due to the fact that blood was returned to the right atrium at a constant rate in the present study. If naloxone administration is associated with an increase in venous return in an intact animal, this increase would be expected to contribute to a greater elevation in arterial pressure than was observed in the present study.

In an animal not on bypass, it would be expected that the naloxone-mediated capacitance volume decrement would be associated with increases in venous return, ventricular enddiastolic pressure, and cardiac output. Because intravascular volume decreases $121 \mathrm{ml}(8.6 \mathrm{ml} / \mathrm{kg})$ in the present study in an animal on bypass without the prior administration of exogenous opiates, it would be expected that mean circulatory filling pressure would increase $4.3 \mathrm{mmHg}$ in a hypotensive animal not on bypass (estimated vascular compliance $2.0 \mathrm{ml} /$ $\mathrm{mmHg} \cdot \mathrm{kg}[24])$. From the work of Guyton and colleagues $(25,26)$, it would be expected that such an increase in mean circulatory filling pressure would be associated with an increase in cardiac output of as much as $60 \%$ in an intact dog, although sinoaortic baroreceptor reflexes and changes in cardiac afterload might modify this effect.

In summary, the present study demonstrates that naloxone administration is associated with a decrease in splanchnic intravascular volume and an increase in extrasplanchnic intravascular volume. The data suggest that the splanchnic volume decrement and extrasplanchnic volume increment are dependent upon the neurogenic release of an unidentified splanchnic hormone. The extrasplanchnic volume increment occurs despite the tendency of naloxone to decrease extrasplanchnic volume through a direct effect on the extrasplanchnic vasculature. Regardless of the mechanisms responsible for the regional volume changes, it is apparent that naloxone administration is associated with a decrease in total intravascular volume and this decrease is due to the decrease in splanchnic volume. Hence, the beneficial effect of naloxone in the experimental treatment of patients with acute hypotension may be due, in part, to mobilization of peripheral blood volume, an increase in venous return, and subsequent enhancement of cardiac output.

\section{Acknowledgments}

We are grateful to Francois W. Pelletier, Laura Weinberg, and Debbie Vaivoda for their surgical assistance and to Amy Filippone and June B. Coons for their help in preparing the manuscript. We thank E. I. du Pont deNemours \& Company (Newark, DE) for supplying the naloxone and Merck Sharpe \& Dohme Research Laboratories (West Point, PA) for supplying the mecamylamine.

The project was supported by National Institutes of Health New Investigator Research Award 1 R23 HL27185 and a grant from the Duberg Cardiovascular Research Fund.

\section{References}

1. Faden, A. I., and J. W. Holaday. 1980. Experimental endotoxin shock: the pathophysiologic function of endorphins and treatment with opiate antagonists. J. Infect. Dis. 143:229-238.

2. Gurll, N. J., D. G. Reynolds, T. Vargish, and R. Lechner. 1982. Naloxone without transfusion prolongs survival and enhances cardiovascular function in hypovolemic shock. J. Pharmacol. Exp. Ther. 220:621-624.

3. Gurll, N. J., T. Vargish, D. G. Reynolds, and R. B. Lechner. 1981. Opiate receptors and endorphins in the pathophysiology of hemorrhagic shock. Surgery. 89:364-369.

4. Vargish, T., D. G. Reynolds, N. J. Gurll, E. M. Ganes, and S. A. Lutz. 1982. The interaction of corticosteroids and naloxone in canine hemorrhagic shock. J. Surg. Res. 32:289-295.

5. Curtis, M. T., and A. M. Lefer. 1980. Protective actions of naloxone in hemorrhagic shock. Am. J. Physiol. 239:H416-H421.

6. Curtis, M. T., and A. M. Lefer. 1981. Beneficial action of naloxone in splanchnic artery occlusion shock. Experientia (Basel). 37:403-404.

7. Faden, A. I., T. P. Jacobs, G. Feuerstein, and J. W. Holaday. 1981. Dopamine partially mediates the cardiovascular effects of naloxone after spinal injury. Brain Res. 213:415-421.

8. Feuerstein, G., C. C. Chiueh, and I. J. Kopin. 1981. Effect of naloxone on the cardiovascular and sympathetic response to hypovolemic hypotension in the rat. Eur. J. Pharmacol. 75:65-69.

9. Gahhos, F. N., R. C. J. Chiu, E. J. Hinchey, and G. K. Richards. 1982. Endorphins in septic shock. Arch. Surg. 117:1053-1057. 
10. Higgins, T. L., E. D. Sivak, D. M. O'Neill, J. W. Graves, and D. G. Foutch. 1983. Reversal of hypotension by continuous naloxone infusion in a ventilator-dependent patient. Ann. Intern. Med. 98:4748.

11. Peters, W. P., P. A. Friedman, M. W. Johnson, and W. E. Mitch. 1981. Pressor effect of naloxone in septic shock. Lancet. 1:529532.

12. Sokal, R. R., and F. J. Rohlf. 1969. Biometry. W. H. Freeman and Co., Inc., San Francisco, CA. 367-376.

13. Dixon, W. J. 1981. BMDP Statistical Software. University of California Press, Berkeley, CA. 105-132.

14. Morrison, D. F. 1976. Multivariate Statistical Methods. McGrawHill Book Co., Inc., New York. 33-34.

15. Bolme, P., K. Fuxe, L. F. Agnati, R. Bradley, and J. Smythies. 1978. Cardiovascular effects of morphine and opioid peptides following intracisternal administration in chloralose-anesthetized rats. Eur. J. Pharmacol. 48:319-324.

16. Laubie, M., H. Schmitt, M. Vincent, and G. Remond. 1977. Central cardiovascular effects of morphinomimetic peptides in dogs. Eur. J. Pharmacol. 46:67-71.

17. Greenway, C. V., and A. E. Lawson. 1966. The effects of adrenaline and noradrenaline on venous return and regional blood flows in the anesthetized cat with special reference to intestinal blood flow. J. Physiol. (Lond.). 186:579-595.
18. Rutlen, D. L., E. W. Supple, and W. J. Powell, Jr. 1981. Betaadrenergic regulation of total systemic intravascular volume in the dog. Circ. Res. 48:112-120.

19. Supple, E. W., and W. J. Powell, Jr. 1981. Effect of acetylcholine on vascular capacity in the dog. J. Clin. Invest. 68:64-74.

20. Synder, S. H., C. B. Pert, and G. W. Pasternak. 1974. The opiate receptor. Ann. Intern. Med. 81:534-540.

21. Lord, J. A. H., A. A. Waterfield, J. Hughes, and H. W. Kosterlitz. 1977. Endogenous opioid peptides: Multiple agonists and receptors. Nature (Lond.). 267:495-499.

22. Wuster, M., R. Schulz, and A. Herz. 1981. Multiple opiate receptors in peripheral tissue preparations. Biochem. Pharmacol. 30: 1883-1887.

23. Dashwood, M. R., and W. Feldberg. 1980. Release of opioid peptides in anaesthetized cats. Br. J. Pharmacol. 68:697-703.

24. Shoukas, A. A., and K. Sagawa. 1971. Total systemic vascular compliance measured as incremental volume-pressure ratio. Circ. Res. 28:277-289.

25. Guyton, A. C. 1955. Determination of cardiac output by equating venous return curves with cardiac response curves. Physiol. Rev. 35:123-129.

26. Guyton, A. C., A. W. Lindsey, and B. N. Kaufman. 1955. Effect of mean circulatory filling pressure and other peripheral circulatory factors on cardiac output. Am. J. Physiol. 180:463-468. 